(C) 2009 CORNELL UNIVERSITY

DOI: $10.1177 / 1938965508328422$

Volume 50, Issue $1 \quad 96-112$

\title{
(Mythical) Revenue Benefits of Reducing Dining Duration in Restaurants
}

by GARY M. THOMPSON

This article tests and calibrates an often repeated assumption about the revenue benefits of reducing dining duration. This assumption is that a reduction in dining duration yields a proportional increase in revenue, so that, for example, a 20 percent reduction in dining duration would yield a 25 percent increase in revenue. This article's simulation-based study of over twelve hundred restaurant scenarios finds that, on average, the revenue bump experienced by reducing the dining duration is less than one-quarter of the amount predicted by the common assumption. Even in the most favorable circumstances, the revenue bump is less than one-half that predicted by the assumption. Thus, while reducing dining duration might result in a marginal increase in revenues, managers should not count on a substantial revenue bump.
Keywords: restaurants, revenue management, capacity management, simulation

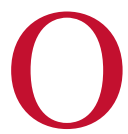
ver the last half dozen years or so, restaurant revenue management has received considerable attention. Much of the work on the topic has come from authors based in the School of Hotel Administration at Cornell University. Professor Sheryl Kimes, the most prolific author on the topic, has written extensively about the tools, or levers, that can be applied to manage restaurant revenue. These tools include managing duration and managing price. In this article, I address duration management.

Although duration management seems to make sense, I was curious to determine the extent to which 
reducing dining duration translates to increased revenues, if at all. Kimes and her coauthors have argued on several occasions that reducing duration would translate into a corresponding proportional increase in revenue (Kimes 1999; Kimes, Wirtz, and Noone 2002; Kimes 2004a, 2004b). Under this assumption, which I will refer to as the "duration reduction assumption," a 20 percent reduction in dining duration would lead to a 25 percent increase in revenue. My aim in this article is to investigate the conditions that affect the validity of this assumption. If it is correct, restaurateurs should pursue this avenue, but if the assumption does not hold, I would suggest that restaurant operators use other revenue management approaches.

To investigate this matter, I developed an extensive simulation-based study of restaurant performance. The results indicate that environmental factors affecting the validity of the assumption include demand intensity, the length of the peak demand window, and customers' willingness to wait for service. I also find that in general, restaurants will capture only a fraction of the revenue expected if the assumption were to hold. Thus, as I explain below, I cannot see how duration management is a viable revenue management tactic, although managers might wish to control table duration for other reasons.

In the remainder of this article, I present a review of the relevant literature, describe the design and present the results of my simulation study, discuss my findings, and offer concluding remarks.

\section{Existing Studies}

Restaurant revenue management can be categorized into issues related to managing capacity, issues related to managing demand, and issues related to implementing those concepts. Professor Sheryl E. Kimes has been the most prolific author on the topic, with articles stretching back to 1998 . Indeed, to my knowledge, the first use of the term restaurant revenue management appears in a 1998 article by Kimes and her coauthors (Kimes et al. 1998).

Some restaurant revenue management articles cover a range of related topics (Kimes 2004a), while others address specific issues, and still others focus on implementation. Specific topics that have been addressed include capacity management (Sill 1991; Sill and Decker 1999), forecasting (Hu, Chen, and McCain 2004), performance evaluation (Reynolds 2004, Reynolds and Thompson 2007), table mixes (Kimes and Thompson 2004, 2005), table combinability (Thompson 2002, 2003), and duration-related issues (Kimes, Wirtz, and Noone 2002; Kimes and Robson 2004; Noone and Kimes 2005; Noone et al. 2007). Implementation-focused articles have used specific restaurants as examples (Kimes et al. 1998; Kimes 2004b). I direct those readers interested in an overview of restaurant revenue management to Kimes's (2004a) report on the topic published by the Cornell Center for Hospitality Research.

To my knowledge, the effects of dining duration on revenue have been addressed at least four times. In the first such study, Kimes (1999) uses an example where a restaurant has one hundred seats, a fourhour peak window, and a sixty-minute mean dining time: "If the meal time can be reduced to 59 minutes, the restaurant can handle an additional 6.8 customers . . . a 1.7 percent increase" (p. 19). The 1.7 percent increase in capacity is the same percentage increase one attains by comparing the old dining duration to the new dining duration $(60 / 59 * 100$ percent).

Kimes, Wirtz, and Noone (2002) and Kimes (2004a) both reference the first Kimes (1999) article, but provide a slightly different example. In this case, the basic scenario is the same: a one hundred-seat 
restaurant, a four-hour peak window, and a sixty-minute mean dining time. However, in this case, "if the dining duration could be reduced to 50 minutes . . . revenue would increase ... [by] 20 percent" (Kimes 2004a, p. 14; Kimes, Wirtz, and Noone 2002, p. 222). The 20 percent revenue increase is the same proportional increase that the old dining duration represents compared to the new dining duration (60/50*100 percent).

Kimes uses the example of a restaurant with annual sales of $\$ 2,358,874$, having $\$ 861,797$ of the sales in the ten "hot" weekly hours. She states that "if dining duration could be decreased from fifty-three minutes [the existing value] to forty-eight minutes, even if seat occupancy remained the same, the annual revenue potential would increase by $\$ 89,771$, or 3.8 percent" (Kimes 2004b, p. 61). Since this extra revenue would be coming from the peak periods only (that is, the only periods where the restaurant was operating at capacity), the percentage increase in revenue during the peak periods is $\$ 89,771 / \$ 861,797$, or 10.4 percent, which is the same percentage increase one gets by dividing the old duration by the reduced duration $(53 / 48 * 100$ percent $=10.4$ percent).

In all these cases, what I define as the "dining reduction assumption" is being applied as a simple capacity calculation to estimate the revenue benefits associated with reducing the dining duration. My focus in this article is testing the validity of that assumption.

\section{Design of the Simulation Study}

A significant problem with the duration reduction assumption concerns how time savings are accumulated from party to party. For example, the assumption would suggest that if a mean dining of sixty minutes is shortened to fifty minutes, then the savings accumulated on the original five parties would enable a sixth to be served in the same length of time (i.e., five parties times sixty minutes per party $=$ six parties times fifty minutes per party). However, the issue becomes when those time savings materialize. In reality, shortening the dining duration from sixty minutes to fifty minutes really only means that you can seat six parties consecutively at a table in the same time that you previously could seat five parties consecutively. Obviously, unless demand at the restaurant persists sufficiently long enough to capture that sixth party, the actual revenue increase will be lower than what the assumption predicts.

To accomplish my stated purpose of testing the validity of the duration reduction assumption, I developed a simulationbased study to investigate the revenue increase that could be achieved by reducing dining duration. Simulation has been used several times in the restaurant revenue management literature (cf. Kimes \& Thompson 2005; Thompson 2002, 2003). An overview of the use of simulation in hospitality contexts can be found in Thompson and Verma (2003).

As listed in Exhibit 1, the study contained nine factors, eight of which were environmental, or largely outside the control of management, and one, the reduction in dining duration, within the control of management. I included four of the environmental factors to ensure I examined a wide range of restaurant environments. These factors are the size of the restaurant, the mean party size, the variation in dining duration within party sizes, and the variation in dining duration across party sizes.

Restaurant size had three levels: 50 seats, 150 seats, and 450 seats. I selected these values to ensure that the study was representative of a significant range of restaurants. Similar restaurant sizes have been used in earlier studies (50-200 seats, Thompson 2003; 230 seats, Kimes and Thompson 2004; 240 seats, Kimes and 


\section{Exhibit 1:}

Experiment Design

\begin{tabular}{|c|c|c|}
\hline Factor & No. of Levels & Level \\
\hline Restaurant size (no. of seats) (factor 1) & 3 & $50,150,450$ \\
\hline Mean party size (no. of covers) (factor 2 ) & 2 & $2.5,3.5$ \\
\hline $\begin{array}{l}\text { Variation in dining duration within party sizes, } \\
\text { measured as a coefficient of variation (factor } 3 \text { ) }\end{array}$ & 2 & $0.3,0.5$ \\
\hline $\begin{array}{l}\text { Variation in dining duration across party sizes, } \\
\text { measured as the ratio of dining duration for } \\
\text { parties of ten people to the dining duration for } \\
\text { parties of one person (factor } 4 \text { ) }\end{array}$ & 2 & $1.5,2.0$ \\
\hline $\begin{array}{l}\text { Peak demand intensity (measured as a proportion } \\
\text { of restaurant capacity) (factor } 5 \text { ) }\end{array}$ & 2 & $0.95,1.05$ \\
\hline $\begin{array}{l}\text { Length of peak demand period, relative to the mean } \\
5 \\
\text { dining duration (factor } 6 \text { ) }\end{array}$ & 9 & $1,1.5,2,2.5,3,3.5,4,4.5$ \\
\hline $\begin{array}{l}\text { Customers' willingness to wait for a table, measured } \\
\text { relative to the mean dining duration for same-sized } \\
\text { parties (factor 7) }\end{array}$ & 3 & $0.333,0.667,1.000$ \\
\hline $\begin{array}{l}\text { Reduction in dining duration (measured as a percentage } \\
\text { of the original duration) (factor } 8 \text { ) }\end{array}$ & 5 & $0 \%, 5 \%, 10 \%, 15 \%, 20 \%$ \\
\hline
\end{tabular}

Thompson 2005). Further, restaurants of 50 to 450 seats constituted 89.7 percent of the sample restaurants in Thompson's (2007) study of table mixes of real restaurants. The two mean party sizes I used were 2.5 and 3.5 people. While the lower average party size is more consistent with the values reported in the literature (approximately 2.6 customers per party, Kimes and Robson 2004), I include the larger party size for thoroughness. Exhibit 2 lists the probabilities of each size party that I used to yield the two mean party sizes.

I used two levels for the within-partysize variation in dining durations: coefficients of variation of 0.3 and 0.5 , which is within the range of 0.16 to 0.5 that has been previously observed (Bell and Pliner 2003; Kimes and Robson 2004). It has been reported several times that larger parties take longer to dine (Bell and Pliner 2003, Kimes and Robson 2004; Kimes and Thompson 2005). I used levels for the relative difference between the mean dining time of the largest parties (ten people) compared to that of the smallest parties (one person): ratios of 1.5 and 2.0. In both instances I used a linear relationship for mean dining time as a function of party size, as illustrated in Exhibit 3.

The other three environmental factors were included since I believed they would be key determinants of the applicability of the duration reduction assumption. These factors are the peak demand intensity, the length of the peak demand window, and customers' willingness to wait for a table. I selected peak demand intensities, measured relative to the capacity of the restaurant, of 0.95 and 1.05 . While a peak demand intensity of 0.95 may seem like the restaurant will not be operating at capacity, this is not the case, because some occupied tables will have unused seats. I assume only even-sized tables, so that, for example, parties of both 1 and 2 people will be seated at two-top tables. Considering table size, then, seating the mean party size of 2.5 people would 


\section{Exhibit 2:}

Party Size Probabilities

\begin{tabular}{lcc}
\hline Party Size & Probability & Probability \\
\hline 1 & 0.290 & 0.100 \\
2 & 0.430 & 0.300 \\
3 & 0.080 & 0.210 \\
4 & 0.070 & 0.140 \\
5 & 0.050 & 0.090 \\
6 & 0.030 & 0.060 \\
7 & 0.020 & 0.040 \\
8 & 0.015 & 0.030 \\
9 & 0.010 & 0.020 \\
10 & 0.005 & 0.010 \\
\hline Mean & 2.50 people & 3.50 people \\
\hline
\end{tabular}

Exhibit 3:

Mean Dining Times by Party Size (Factor 2)

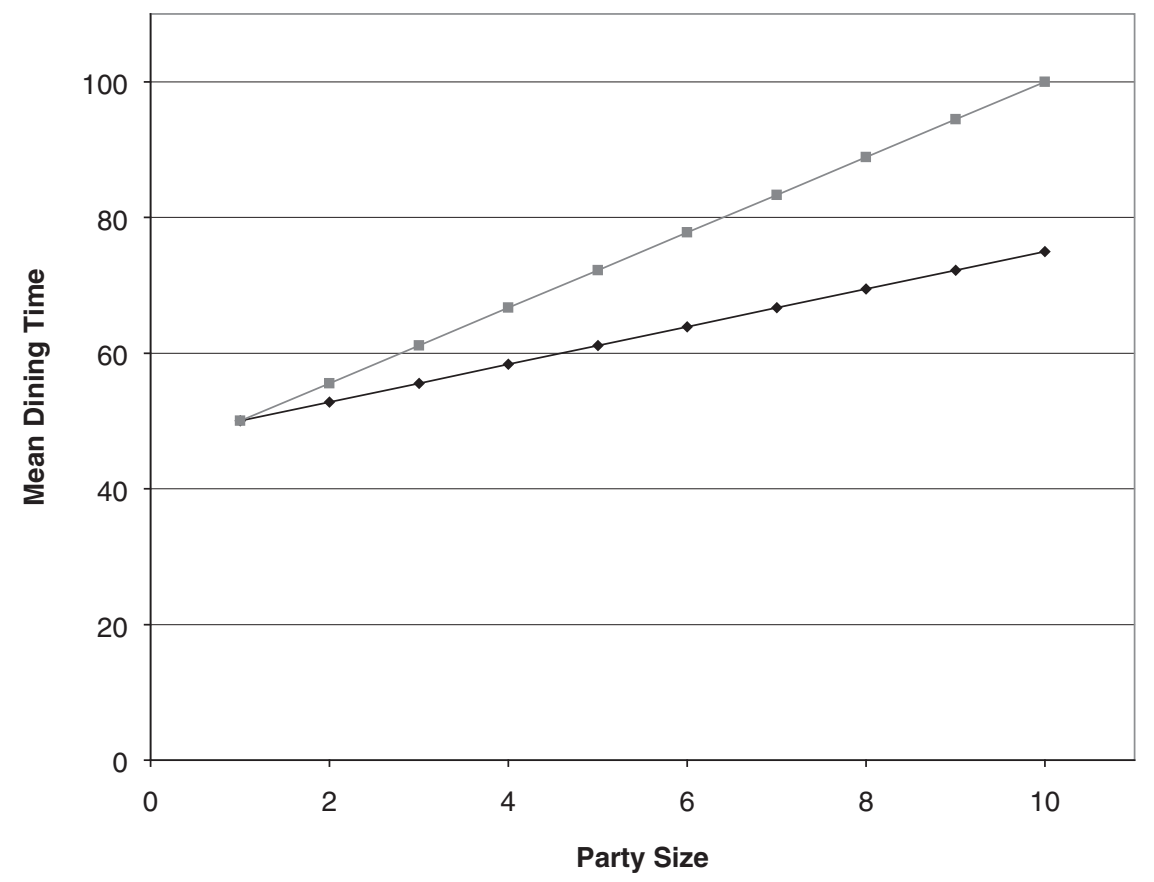

$\rightarrow$ Low Variation $\quad \rightarrow-$ High Variation 
require an average of 2.95 seats, giving a best achievable space utilization of 84.7 percent. The mean party size of 3.5 people would require an average of 3.96 seats, giving a best achievable space utilization of 88.4 percent. Thus, even the lowest level of peak demand intensity represents more demand than there is capacity to serve. It seems quite obvious that if demand intensity is not sufficiently high, reducing dining duration will not yield additional revenue.

A factor that I believe will be a strong determinant of the applicability of the duration reduction assumption is the length of the peak demand window. If the peak demand window lasts only as long as it takes to turn the tables one time, then it is likely there will not be sufficient customers available at the end of the first table turn to fill the tables a second time, even with a reduced dining duration. To test this, I used nine levels for the length of the peak demand window: starting with 1.0 times and increasing by 0.5 until I reached 5.0 times the mean dining duration. With a peak demand window equal to five times the mean dining duration, the tables should be turned at least five times, on average, with the original dining durations.

The final factor that I believed would influence the validity of the duration reduction assumption is customers' willingness to wait for a table. Having customers who are willing to wait for a table should have a comparable effect to lengthening the peak demand window, and so increase the number of customers who can be served at the end of the peak window. Again, the more customers who can be served toward the end of the peak, the more applicable the duration reduction assumption. I used three levels for customers' willingness to wait for tables, equal to $0.333,0.667$, and 1.000 times the mean dining duration for samesized parties.
With respect to the factors that I believe will influence the applicability of the duration reduction assumption, I have three hypotheses, related to the rationales presented above:

Hypothesis 1: The duration reduction assumption will be more valid when peak demand intensity is higher.

Hypothesis 2: The duration reduction assumption will be more valid when the peak demand window is longer.

Hypothesis 3: The duration reduction assumption will be more valid when customers are willing to wait longer for a table.

Study assumptions. In all, I applied fifteen assumptions in the simulation study, which was intended to ensure a tractable study. I do not believe that any of the assumptions would have an effect on the duration reduction assumption. First, I assumed that there were only parties of one to ten people. While parties of ten do occur in restaurants, they tend to be uncommon, so I am not concerned that this assumption on party sizes limits the results. Second, I assumed that parties would be seated at only a single table, and not split across tables. While relaxing this assumption may, in fact, increase the effectiveness of the table utilization of the restaurant, there is no reason to think it would affect the duration reduction assumption. Third, I assumed that tables would not be combined (combining two two-tops to create a four-top table). I consider this to be a nonlimiting assumption since it has earlier been demonstrated that noncombinable tables work better in most restaurants (Thompson 2002). Fourth, I assumed that only tables with even numbers of seats were allowed. Again, while relaxing this assumption may in fact increase the space utilization of a restaurant, I see no reason that it would affect the 
duration reduction assumption. Fifth, I assumed that the space required by a table was proportional to its number of seats. I grant the reader that this assumption is often violated in practice, since tables with fewer seats tend to use proportionally more space. However, I again do not believe that the assumption would affect the applicability of the duration reduction assumption. Sixth, I assumed that every customer had the same value, even though it is commonly the case that smaller parties spend more per person. I made this assumption to ensure that the table optimization was not "cherrypicking" the most valuable parties, but rather that all parties were served with equal likelihood. Eighth, I assumed that the restaurant did not take reservations and operated only with walk-ins. While many restaurants take, or require, reservations, using only walk-ins allows me to focus directly on the arrival (and wait time) of parties, without the compounding complexity imposed by simulating reservations. Ninth, I assumed a Poisson arrival process (exponential times between customer arrivals). This time distribution is common in real settings, since it captures the phenomenon that customers tend to arrive not uniformly, but in bunches. Tenth, I assumed that dining durations were lognormally distributed. Lognormal distributions tend to be common in restaurant settings, since the distribution captures the nature of those parties who tend to linger over their meals (the distribution has a longer right tail than does a normal distribution). Eleventh, I assumed that customers would wait until their designated limit (which was based on the experimental factor and their party size), and would depart at that time if they had not been seated. This assumption seems realistic, since most large parties are willing to wait longer for tables than are short parties (given that large parties recognize that it can take a restaurant a longer time to make available a table of the necessary size). Twelfth, I assumed that there was no limit on the number of waiting parties. I made this assumption to ensure that it was only the customers' willingness to wait, and not the size of the waiting area, that determined whether a party would be lost. Thirteenth, I assumed that demand would build to its peak evenly over a one-hour period. Specifically, in each of the first four fifteen-minute periods of operation, party arrivals were set at 20 percent, 40 percent, 60 percent, and 80 percent of the peak party arrival rate. I made this assumption simply to reflect the fact that, in my experience, most restaurants choose to open earlier than their peak demand period. Fourteenth, I assumed that at the end of the peak demand window, demand would decline evenly over an hourlong period. I implemented this similarly to the ramp-up in demand prior to the peak demand period. Finally, I simulated one hundred days of operation of the restaurant under each of the study conditions. Using one hundred days helps ensure that differences in my results are a true effect, and not simply an artifact of the random variation that one can see in short simulations. In addition, the one hundred days corresponds to about a year's worth of Friday and Saturday evenings, which are often the peak demand periods in restaurants.

Simulation study process. The combinations of the seven environmental factors yielded a total of 1,296 different scenarios $(3 * 2 * 2 * 2 * 2 * 9 * 3)$. I evaluated the effect of reducing the dining duration in each of these scenarios. I started with the original dining durations, and investigated dining duration reductions of 5 percent, 10 percent, 15 percent, and 20 percent of the original durations. The combination of the 1,296 scenarios and five dining durations resulted in a total of 9,720 observations in the simulation study. To control unnecessary variance in the simulation, within each of the 1,296 scenarios I held the party 


\section{Exhibit 4:}

Results by Restaurant Size, in Seats (Factor 1)

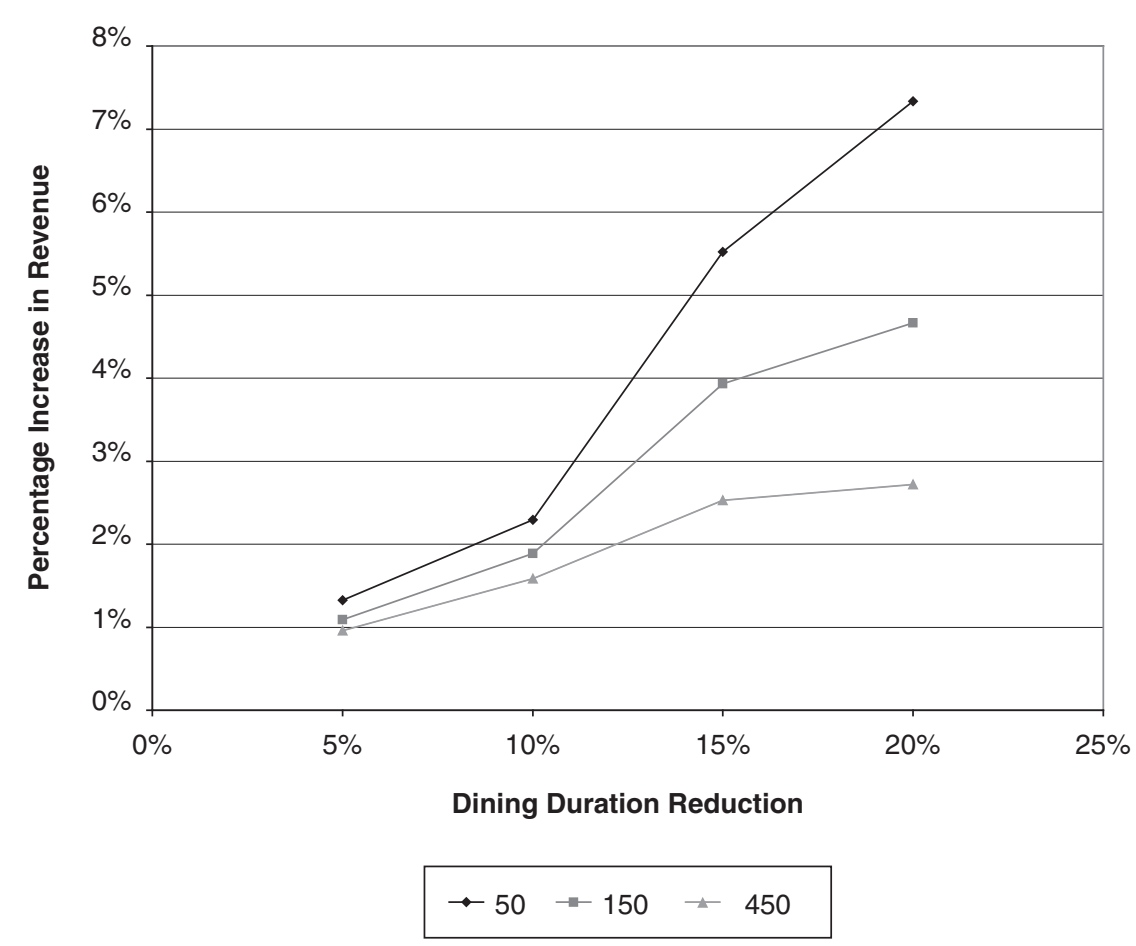

arrival times and party sizes the same across the different dining durations, and used proportionally the same dining durations. As an example, if, in the forty-fifth scenario, the sixth party arrived at 5:08 PM and contained six people and took $50 \mathrm{~min}$ utes to dine under the original dining duration, then for the factor levels of a 5 percent, 10 percent, 15 percent, and 20 percent reduction in dining duration, the sixth party would still arrive at 5:08 PM and contain six people, but durations would decline first to 47.5 minutes, then 45 minutes, then 42.5 minutes, and finally, 40 minutes.

For each of the 9,720 observations in the study, I found the recommended table mix using the simulated annealing-naïve approach presented by Kimes and Thompson
(2005). This approach to finding a recommended table mix begins with the naïve table mix (Thompson 2002) and then uses a one hundred-iteration simulated annealing-based search process. The study I completed with Kimes reported that this approach finds table mixes that generate revenue within 0.1 percent of the best possible that can be found with an exhaustive search of all possible table mixes. Given the large number of scenarios I was examining, and given that the largest restaurant size would have 1,032,126 unique table mixes (of the table sizes I allowed), I deemed an exhaustive search to be impractical. Having found the recommended table mix, I recorded the revenue achieved for that combination of scenario and dining duration reduction. 
Exhibit 5:

Results by Level of Mean Party Size (Factor 2)

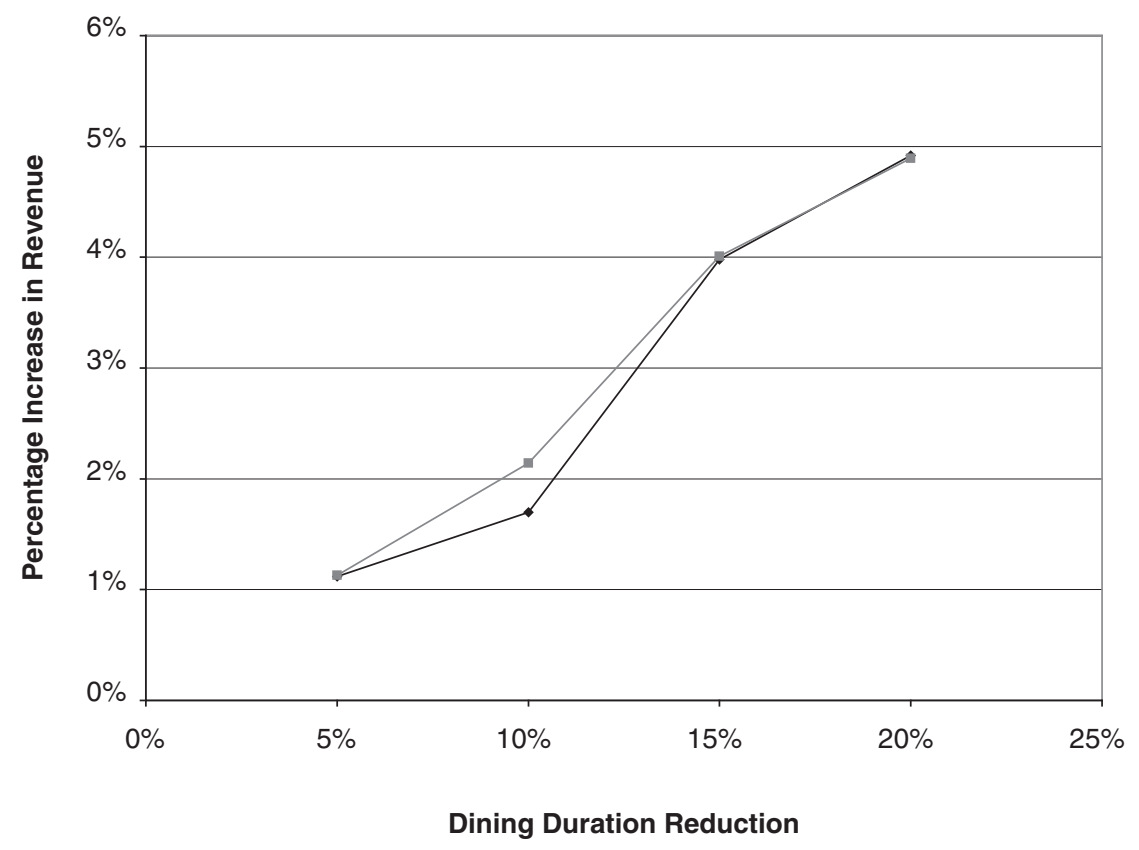

$\rightarrow 2.5 \rightarrow-3.5$

\section{Results of the Simulation Study}

I begin by presenting exhibits that illustrate the effect on revenue of reducing the dining duration, for the different experimental factors and levels. The results by restaurant size (Exhibit 4) were quite surprising, with revenue increases coming from duration reductions being inversely related to the size of the restaurant. The best explanation for this is simply due to the lower degrees of freedom in the small restaurant. By definition, smaller restaurants have fewer tables of a given size, and so if a particular party runs long, then it becomes more likely that customers needing that size table will wait longer, and perhaps be lost. Reducing the duration in small restaurants, then, can make it less likely that potential customers will be lost due to long waits.

Considering the effect of mean party size on revenue increases offered by dining duration reductions (Exhibit 5), I see few differences in revenue increases. It was only at the 10 percent reduction in dining duration that there was any notable difference, and the larger mean party size yielded a greater revenue improvement than the smaller party size.

Exhibit 6 shows that the dining duration within party sizes had only a small effect on the revenue increases associated with reducing the dining duration. Interestingly, the revenue increases were greater with 


\section{Exhibit 6:}

Results by Level of Variation in Dining Times within Party Sizes (Factor 3)

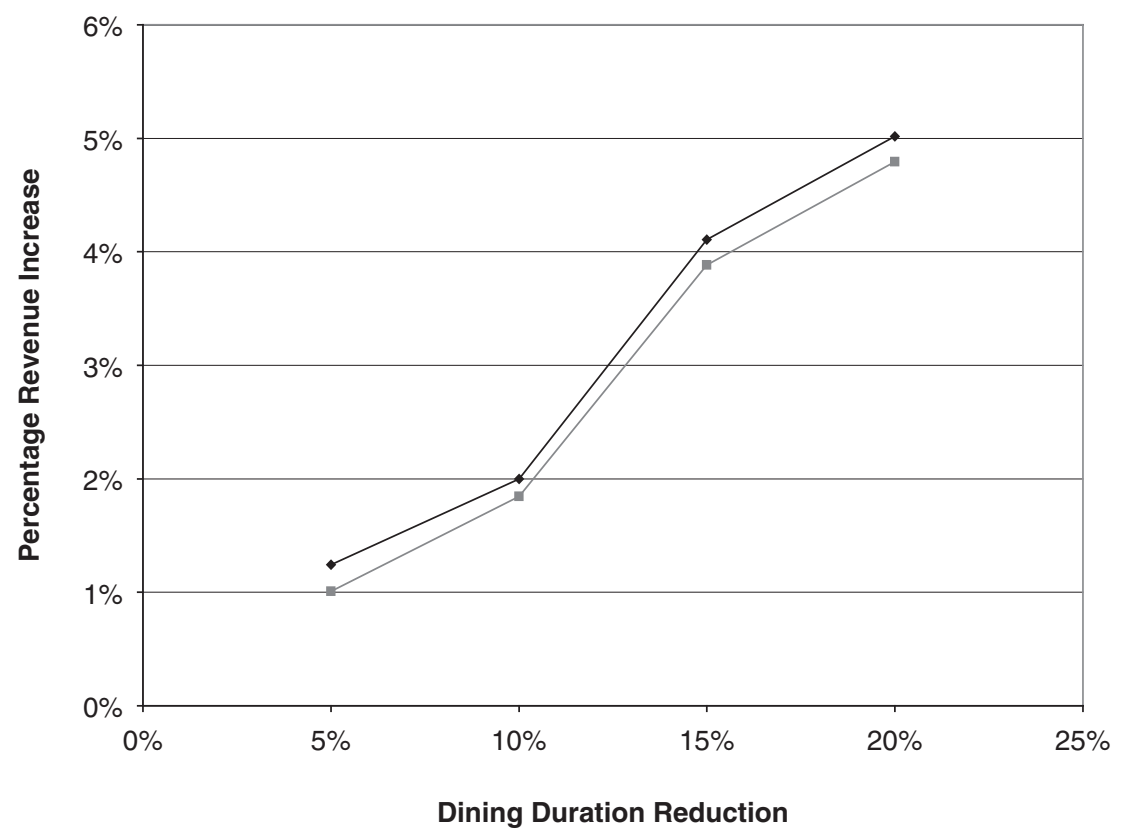

lower variation in within-party-size dining durations.

Another interesting result is displayed in Exhibit 7. Revenue increases were greater, across all dining duration reductions, with greater variation in dining times across party sizes. The explanation for this may be related to customers' willingness to wait for a table, which I implemented as a multiple of the mean dining duration for same-sized parties. As the variation in dining time across party sizes increases, the overall length of time parties are willing to wait increases, which has the effect of increasing the length of the demand period (meaning more parties can be served toward the end of the peak demand period).
Exhibit 8 shows that the revenue increases achieved from reducing the dining durations were higher with higher demand intensities. Higher demand intensities presumably mean that there is a bigger backlog of customers that are available to be served when the dining duration is reduced.

As I anticipated, longer peak dining windows yield greater revenue increases associated with reduced dining duration (Exhibit 9). Clearly, then, a big determinant of the applicability of the duration reduction assumption is the length of the peak demand window: the shorter the peak window, the less applicable the assumption.

Exhibit 10 illustrates the results with respect to customers' willingness to wait 


\section{Exhibit 7:}

Results by Level of Variation in Dining Times across Party Sizes (Factor 4)

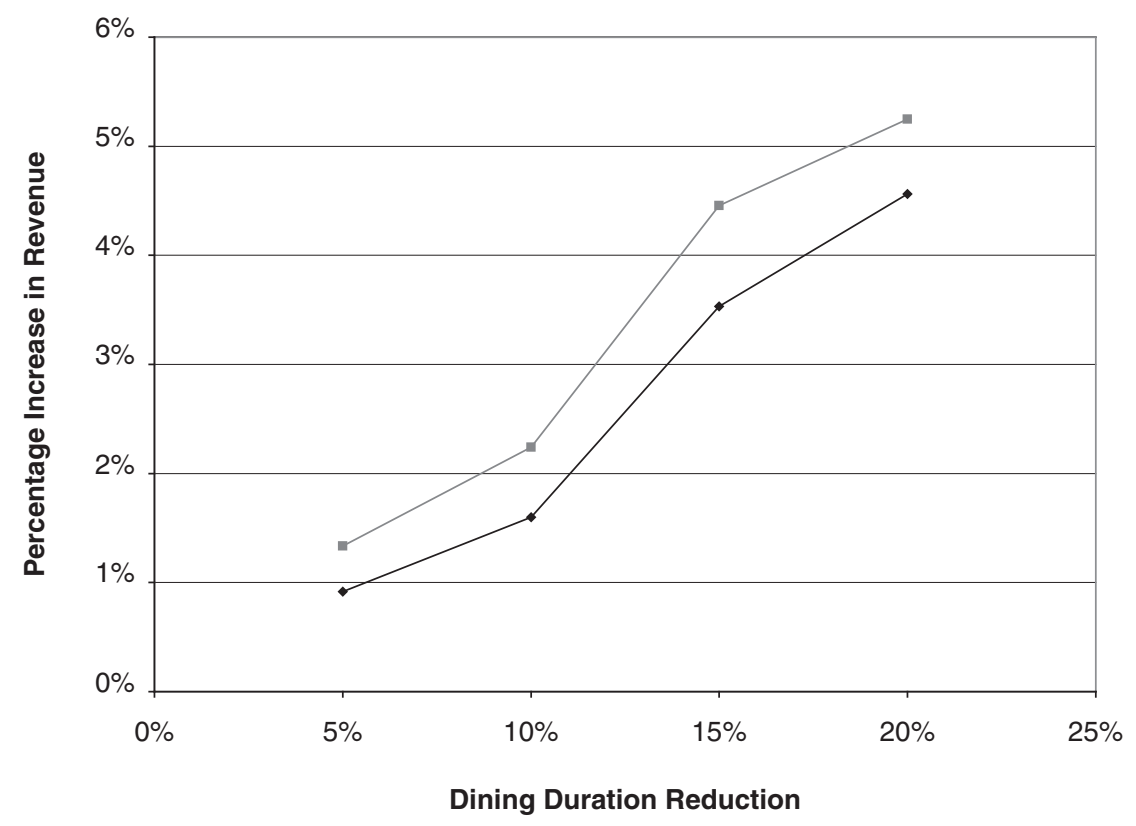

$\rightarrow 1.5 \rightarrow 2$

for a table. My hypothesis, that the duration reduction assumption would be better supported with a greater willingness to wait, is partially supported by the results, in that there was a noticeable difference in the revenue increase at the 5 percent and 10 percent duration reductions, when customers' willingness to wait increased from one-third to two-thirds of the meaning dining duration. However, there appeared to be no revenue benefit from customers' being willing to wait longer than twothirds of the mean dining duration.

All of the graphs in Exhibits 4 through 10 display an uncharacteristic $S$ shape. Typically, I would have expected either more linear performance or a smooth convex (or concave) performance. The best explanation I have for this shape is that the revenue increase is not linear with respect to duration reductions. Small reductions in duration may yield little increase in revenue because the small reductions do not enable the capture of another table turn at the end of the peak period. As the duration is further reduced, however, it allows some additional tables to be turned. As this repeats, what emerges is a step pattern in the relationship, which appears as an $S$ since we are seeing only two of the steps and one riser.

I next turn my attention to the overall results of the simulation study, which are reported in Exhibit 11. The actual revenue increases yielded by the reducing dining durations were well below what would 


\section{Exhibit 8:}

Results by Level of Demand Intensity (Factor 5)

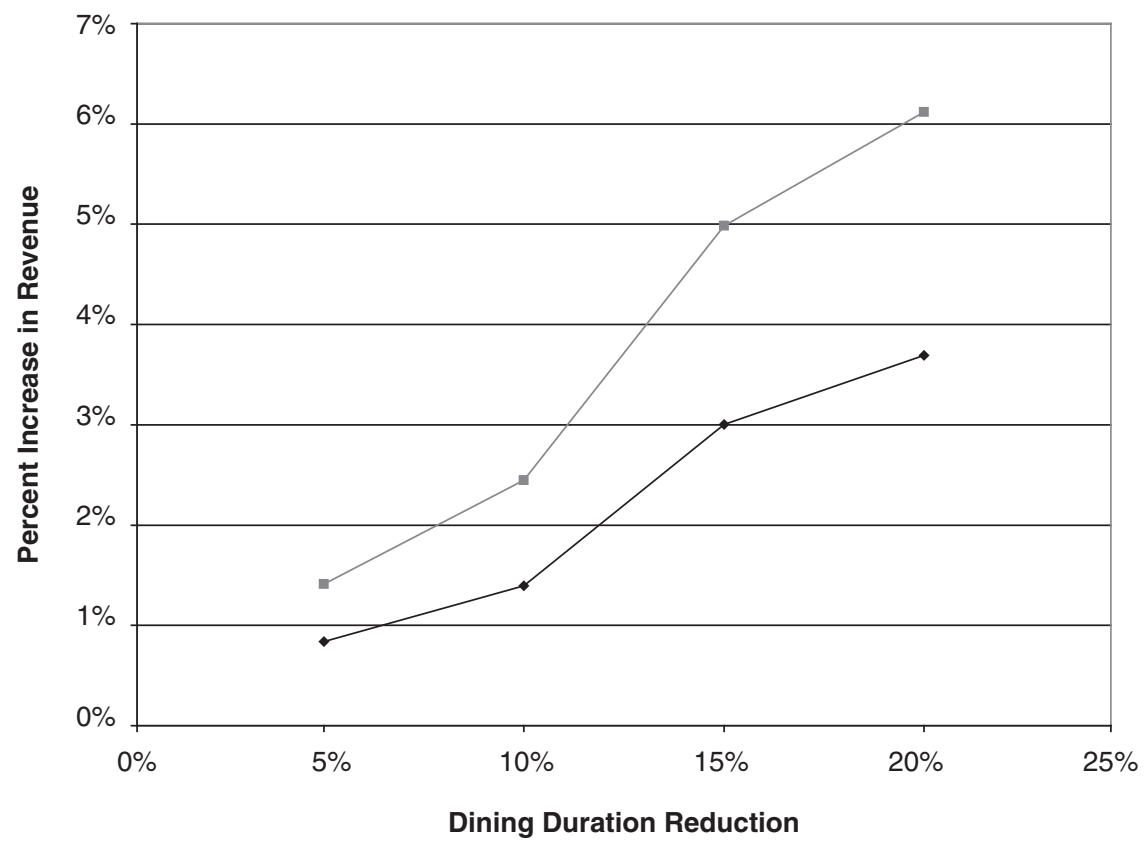

have been expected, had the duration reduction assumption held. For example, if the assumption applied, then reducing the dining duration by 5 percent should have increased revenue by 5.3 percent $(1.0 / 0.95 * 100$ percent). However, across the 1,296 simulated scenarios, reducing the dining duration by 5 percent increased revenue by only 1.1 percent, or 21.4 percent of what would have been expected.

Even considering the environments where reducing the dining duration had the biggest effect, the results were below what the duration reduction assumption predicted. As described earlier in the examination of Exhibits 4 through 10, the revenue increases achieved by reducing the dining duration were greatest: with the smallest restaurant size, under the higher level of variability in dining durations across party sizes, under the highest level of demand intensity, and with the longest peak demand window. In the twelve scenarios meeting these conditions (originating from the two levels of mean party sizes, times two levels of within-party dining duration variation, times the three levels for customers' willingness to wait for tables), revenue increased between 2.1 percent at the 5 percent reduction in dining duration and 9.9 percent at the 20 percent reduction in dining duration. These values at best are less than one-half what would be expected, if the duration reduction assumption were to hold.

Exhibit 12 presents the outcome of a regression analysis on the study results. 


\section{Exhibit 9:}

Results by Length of the Peak Demand Window (Factor 6)

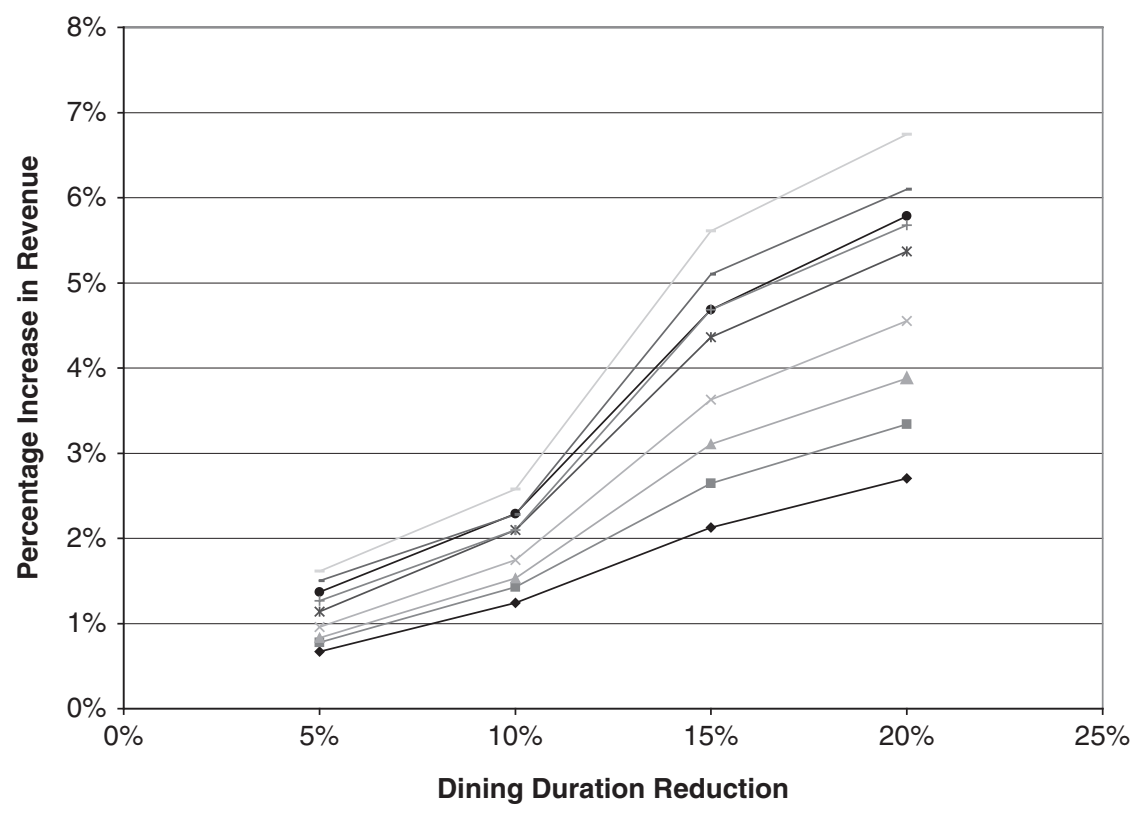

$\rightarrow-1 \rightarrow-1.5 \rightarrow 2-2.5 \rightarrow-3$

$\rightarrow-3.5-4-4.5-5$

The dependent variable was the proportional increase in revenue, compared to the revenue attained under the original dining durations. Since the original dining duration became the reference point, there were 5,184 observations in the data set $(1,296$ scenarios $* 4$ dining duration reductions). The independent variables were the actual values of each factor level. Overall, the regression was significant at $p<.001$ level, and explained over 71 percent of the variation in the proportional revenue increase. A test of the regression errors showed them to be normally distributed. All of the simulation study factors were statistically significant at the .001 level, with the exception of mean party size, which was significant at the .01 level. The actual regression equation, which I will call the revenue increase prediction function, is

Proportion Increase in Revenue $=-0.18936-$ $0.000049 *$ Number of Seats $+0.001147 *$ Mean

Party Size $-0.01048 *$ WPSDurVar + $0.0133364 *$ APSDurVar + 0.150764*

DmdInt $+0.005964 *$ PDWLen + $0.005964 *$ CW2Wait $+0.268275 *$ DRProp,

where

WPSDurVar $=$ Variation in Dining Duration within Party Sizes = coefficient of variation of dining duration for all party sizes,

APSDurVar $=$ Variation in Dining Duration across Party Sizes $=($ mean dining time for parties of ten people)/

(mean dining time for parties of one person), 


\section{Exhibit 10:}

Results by Level of Customers' Willingness to Wait for a Table (Factor 7)

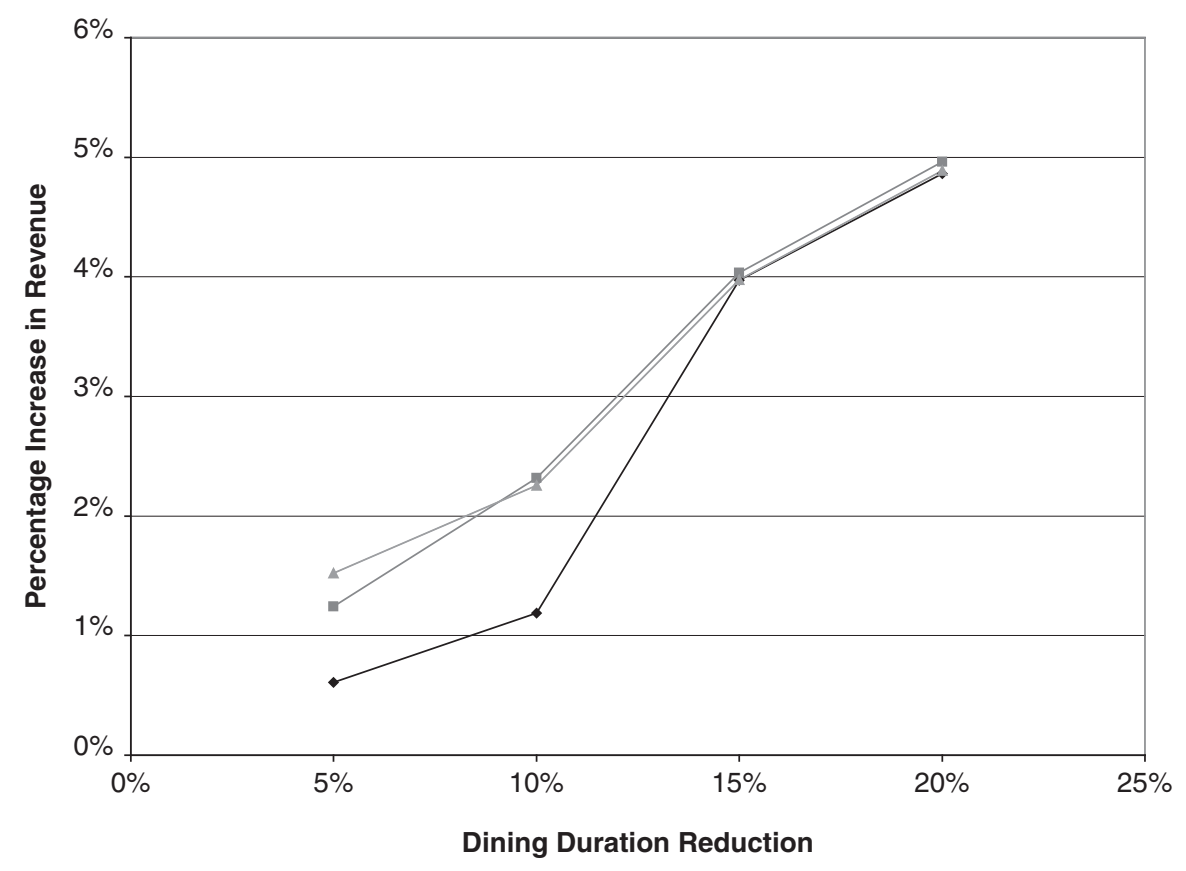

$\rightarrow 0.333 \rightarrow 0.667 \rightarrow 1.000$

\section{Exhibit 11:}

Results Summary (in percentages)

\begin{tabular}{|c|c|c|c|c|}
\hline & \multicolumn{4}{|c|}{ Reduction in Dining Duration } \\
\hline & $5 \%$ & $10 \%$ & $15 \%$ & $20 \%$ \\
\hline $\begin{array}{l}\text { Expected increase in revenue (based on the } \\
\text { duration reduction assumption) }\end{array}$ & 5.3 & 11.1 & 17.6 & 25.0 \\
\hline $\begin{array}{l}\text { Average increase in revenue (across the 1,296 } \\
\text { simulated scenarios) }\end{array}$ & 1.1 & 1.9 & 4.0 & 4.9 \\
\hline $\begin{array}{l}\text { Percentage of expected revenue increase } \\
\text { actually acheived }\end{array}$ & 21.4 & 17.3 & 22.6 & 19.6 \\
\hline "Best achievable" increase in revenue ${ }^{a}$ & 2.1 & 2.9 & 8.1 & 9.9 \\
\hline $\begin{array}{l}\text { "Best achievable" increase in revenue as a } \\
\text { percentage of the expected revenue increase }\end{array}$ & 39.0 & 26.3 & 45.8 & 39.6 \\
\hline
\end{tabular}

a. Under the twelve scenarios with the highest level of demand intensity, the higher level of variation in dining durations across party sizes, the smallest restaurant size, and the longest peak demand window. 
DmdInt $=$ Demand Intensity $=$ parties expected per hour*(sum across party sizes, of party size*original mean duration for parties of that size* probability of that size party)/(number of seats*sixty minutes),

PDWLen $=$ Length of the Peak Demand Window $=($ length of the peak demand window, in hours)/(mean dining duration in hours, based on the original duration),

CW2Wait $=$ Customers' Willingness to Wait $=$ (length of time customers are willing to wait, in hours)/(mean dining duration in hours, based on the original duration), and

\section{DRProp $=$ Duration Reduction Proportion $=$ 1 - (new mean dining duration)/ (original mean dining duration)}

The signs of the independent variables in the revenue-increase prediction function indicate that proportional revenue increases are greater with fewer seats, larger mean party sizes, less variation in dining duration in dining duration within party sizes, more variation in dining duration across party sizes, higher demand intensity, longer peak demand windows, longer willingness to wait on the part of customers, and greater reductions in dining duration. These results are consistent with what was displayed in Exhibits 4 through 10, and also support my three hypotheses about the applicability of the duration reduction assumption.

\section{Discussion}

To reiterate my earlier definition, the duration reduction assumption, which has been applied several times in the restaurant revenue management literature, assumes that a reduction in dining duration leads to a proportional (and substantial) increase in revenue. While I made a number of assumptions in my simulationbased study of 1,296 restaurant scenarios, the study did cover a wide variety of restaurant scenarios. Moreover, I believe that relaxing the assumptions is unlikely to have any notable effect on my findings, as I explained earlier. For example, while I assumed that the restaurant accepted only walk-in parties (i.e., no reservations were taken), there is no reason to believe that the results would not hold in restaurants that take reservations.

These findings - that the revenue bump that can be attained by reducing dining duration is much less than what would be expected if the duration reduction assumption holds, in other words, that the expected revenue bump is mythical-have a number of important implications. First, and perhaps most important, managers who apply the duration reduction assumption to judge the benefit they would achieve by reducing dining duration are going to be disappointed with their results. Second, since the duration reduction assumption gives a false, overly optimistic estimate of the revenue benefits of reducing the duration, it makes it impossible for managers to evaluate the cost-benefit trade-offs of reducing duration as compared to other actions they could take to drive revenue. Third, my results question the practice of reducing duration to achieve a revenue bump. Even in the most favorable scenarios, the revenue bump was less than half what was expected. This becomes even more important because of two other considerations. First, operationally it becomes more challenging to deliver meals faster, which may necessitate hiring additional staff. Second, only certain portions of the dining experience that can, in fact, be speeded up without jeopardizing customer satisfaction (Noone and Kimes 2005; Noone et al. 2007). These portions are what could be considered as restaurant paced-for example, the time to deliver menu items after customers order, the time to bus the table, and the time to reseat another party-as compared to the portions for which the customers set the pace, 


\section{Exhibit 12:}

Regression Results

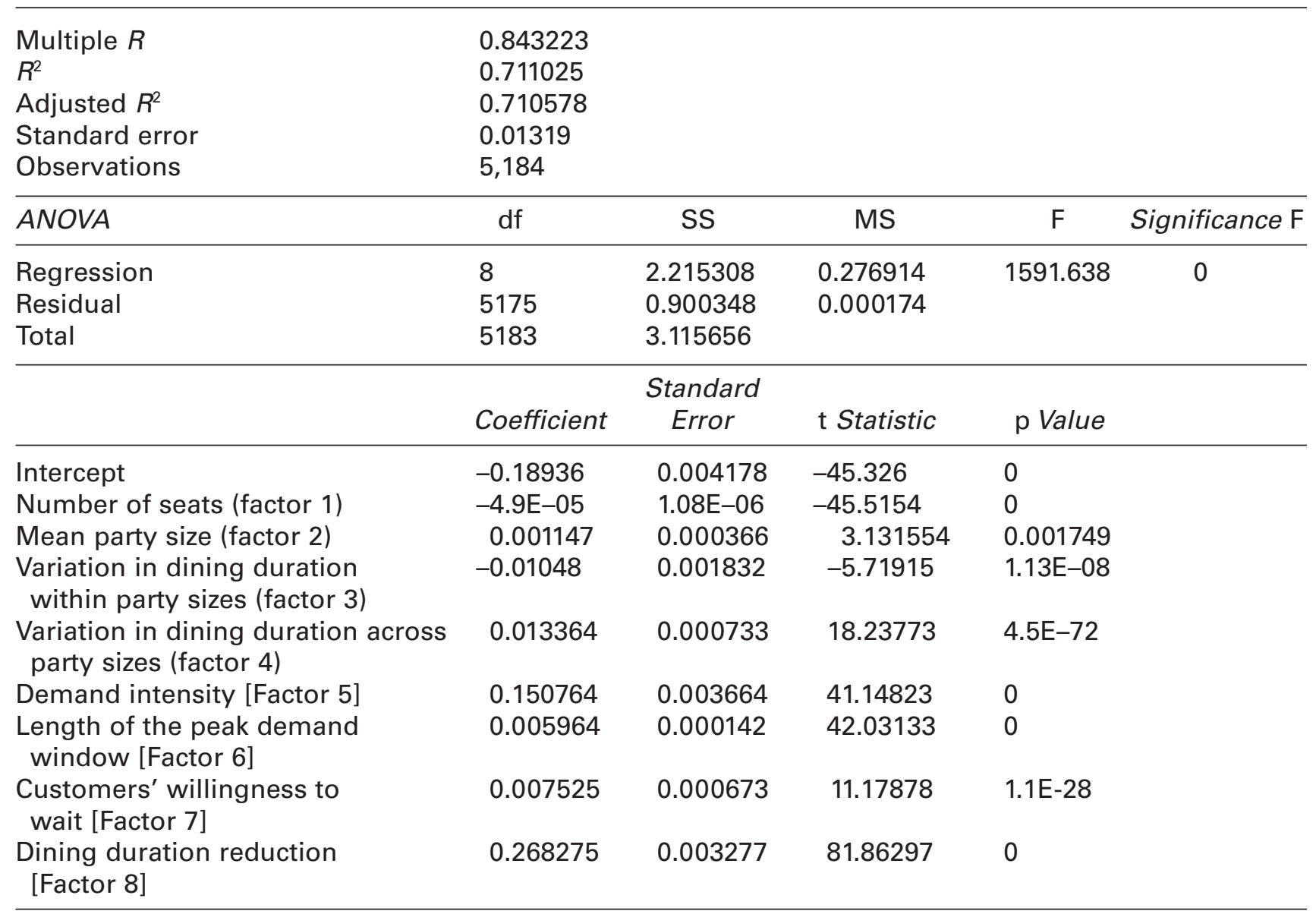

most particularly, the time for them to consume the food at their preferred pace.

Based on all of these concerns, I recommend that the managers (and academics) abandon the duration reduction assumption in its current form. All is not lost, however. My three hypotheses were supported, and the revenue increase prediction function (i.e., the regression equation) was a strong predictor of the revenue bump that would be expected from reducing duration, explaining over 70 percent of the variation in revenue increase. Using this function can give a much more accurate prediction of the revenue increase accruing from reducing duration as compared to simply applying the duration reduction assumption.

\section{Conclusions}

Perhaps the most important lesson from this study is that back-of-the-envelope capacity calculations, such as those in the duration reduction assumption, are not particularly appropriate in complex service environments. A much better approach, obviously, is to build a simulation model that captures the nuances and interdependencies in a real system. Without going to 
that level of effort, restaurant managers who wish to estimate the revenue improvements they would achieve by having their employees perform certain parts of the dining process faster should be well served by using the revenue increase prediction function I presented.

\section{References}

Bell, Rick, and Patricia L. Pliner. 2003. Time to eat: The relationship between the number of people eating and meal duration in three lunch settings. Appetite 41:215-18.

Hu, Clark, Ming Chen, and Shiang-Lih Chen McCain 2004. Forecasting in short-term planning and management for a casino buffet restaurant. Journal of Travel and Tourism Marketing 16 (2/3): 79-98.

Kimes, Sheryl E. 1999. Implementing restaurant revenue management: A five-step approach. Cornell Hotel and Restaurant Administration Quarterly 40 (3): 16-21.

-. 2004a. Restaurant revenue management. Reports of the Center for Hospitality Research 4 (2): 3-34.

. 2004b. Restaurant revenue management: Implementation at Chevys Arrowhead. Cornell Hotel and Restaurant Administration Quarterly 45 (1): 52-67.

Kimes, Sheryl E., Deborah I. Barrash, and John E. Alexander. 1999. Developing a restaurant revenue management strategy. Cornell Hotel and Restaurant Administration Quarterly 40 (5): 18-30.

Kimes, Sheryl E., Richard B. Chase, Sunmee Choi, Philip Y. Lee, and Elizabet N. Ngonzi. 1998. Restaurant revenue management: Applying yield management to the restaurant industry. Cornell Hotel and Restaurant Administration Quarterly 39 (3): 32-39.

Kimes, Sheryl E., and Stephani K. A. Robson. 2004. The impact of restaurant table characteristics on meal duration and spending. Cornell Hotel and Restaurant Administration Quarterly 45 (4): 333-46.

Kimes, Sheryl E., and Gary M. Thompson. 2004. Restaurant revenue management at Chevys: Determining the best table mix. Decision Sciences 35 (3): 371-92.
2005. An evaluation of heuristic methods for determining the best table mix in full-service restaurants. Journal of Operations Management 23 (6): 599-617.

Kimes, Sheryl E., Jochen Wirtz, and Breffni M. Noone. 2002. How long should dinner take? Measuring expected meal duration for restaurant revenue management. Journal of Revenue and Pricing Management 1 (3): 220-33.

Noone, Breffni M., and Sheryl E. Kimes. 2005. Dining duration and customer satisfaction. Reports of the Center for Hospitality Research 5 (9): 4-21.

Noone, Breffni M., Sheryl E. Kimes, Anna S. Mattila, and Jochen Wirtz. 2007. The effect of meal pace on customer satisfaction. Cornell Hotel and Restaurant Administration Quarterly 48 (3): 231-45.

Reynolds, Dennis. 2004. An exploratory investigation of multiunit restaurant productivity assessment using data envelopment analysis. Journal of Travel and Tourism Marketing 16 (2/3): 19-26.

Reynolds, Dennis, and Gary M. Thompson. 2007. Multiunit restaurant productivity assessment using data envelopment analysis. International Journal of Hospitality Management 26 (1): 20-32.

Sill, Brian T. 1991. Capacity management: Making your service delivery more productive. Cornell Hotel and Restaurant Administration Quarterly 31 (4): 77-87.

Sill, Brian T., and Robert Decker. 1999. Applying capacity-management science: The case of Browns Restaurants. Cornell Hotel and Restaurant Administration Quarterly 40 (1): 22-30.

Thompson, Gary M. 2002. Optimizing a restaurant's seating capacity: Use dedicated or combinable tables? Cornell Hotel and Restaurant Administration Quarterly 43 (3): 48-57.

2003. Optimizing restaurant table configurations: Specifying combinable tables. Cornell Hotel and Restaurant Administration Quarterly 44 (1): 53-60. - 2007. Restaurant capacity effectiveness: Leaving money on the tables. Reports of the Center for Hospitality Research 7 (7): 4-13.

Thompson, Gary M., and Rohit Verma. 2003. Computer simulation in hospitality teaching, practice and research. Cornell Hotel and Restaurant Administration Quarterly 44 (2): 85-93.

Gary M. Thompson, Ph.D., is a professor of operations management at the Cornell University School of Hotel Administration (gmt1@cornell.edu). 